\title{
Performance of Outdoor Lamp Implementation for Visible Light Communication under Ambient Environment
}

\author{
Ronaldo Soritua Sitanggang ${ }^{1}$, Denny Darlis ${ }^{1}$, Karina Wahyu Noviyanti ${ }^{1}$ \\ ${ }^{1}$ Diploma of Telecomunication Engineering, School of Applied Science, \\ Telkom University, Bandung, Indonesia \\ * denny.darlis@tass.telkomuniversity.ac.id
}

\begin{abstract}
Visible Light Communication is the name given to wireless communication systems that convey information by modulating visible light by the human eye. Interest in the field of VLC has grown rapidly along with the development of LEDs as a source of lighting. The motivation is clear: If the room is lit by an LED, why not use it further for the communication provider, along with the lighting facilities at the same time? At the sending side, VLC technology uses LED lighting lamps which are currently very popular to replace incandescent lamps and TL (Fluorescent Lamp) lamps. Visible light communication has many advantages, including security, speed, and convenience to be applied to users to send various types of information including digital data such as text and images. Several studies have been conducted previously regarding the application of information delivery systems using VLC such as sending voice, digital data, images, and video. However, it has not been clearly stated the influence of various lighting lamps used on the system mentioned above such as electrical and optical power used, the angle of transmission and optimal distance with the influence of environmental conditions that cause information transmission losses. Data that can be sent well use yard lighting with a maximum distance of $130 \mathrm{~cm}$ with $15 \mathrm{~lx}$ light intensity, street lighting with a maximum distance of $400 \mathrm{~cm}$ with $61 \mathrm{x}$ light intensity, and vehicle lights with a maximum distance of $270 \mathrm{~cm}$ with 121x light intensity.
\end{abstract}

\section{Introduction}

Visible Light Communication (VLC) is the name given to wireless communication systems that convey information by modulating visible light by the human eye. Interest in the field of VLC has grown rapidly along with the development of LEDs as a source of lighting. The motivation is clear: If the room is lit by an LED, why not use it further for the communication provider, join the lighting facilities at the same time?

The IEEE 802.15.7 Task Force on Visible Light Communication, has developed the PHY (Physical Layer) and MAC (Media - Access Control) layer standards for VLC in 2009. IEEE 802.15.7 VLC has three different PHYs depending on the application: PHY I, PHY II, and PHY III. PHY I is intended for outdoor use with low data rate applications. This mode uses on-off keying $(\mathrm{OOK})$ with data rates in tens to hundreds of $\mathrm{kb} / \mathrm{s}[1][2]$.

The purpose of this research is to determine the characterization of several low cost LED lamps which we can buy from surrounding market when sending data using VLC. We choose an LED floodlights[3], an LED street lights[4], and an LED motorcyle headlights[5] with some electronic circuit 
modification to find out how far data can be sent through the lights. The LED lights will be affected under the influence of sunlight and other lighting sources that do not have VLC features.

This article consisted of 5 sections. Section 1 is the introduction parts. Section 2 presents the related work of this research. Section 3 describes the design implementation. The discussion are presented in section 4 . And the last section 5 is the conclusion of this article.

\section{Literature review}

To give more description about the performance of the VLC transmitter, this section shows some works from related field.

Many research in VLC are deployed in indoor environment [6]. In [7], authors analyzed that sending digital data in the form of text through VLC using only one LED and uses a USB to TTL converter. In [8] the VLC system can transmit many kind of digital data such as text, image and video over $2 \mathrm{~m}$. And [9] showed the implementation of VLC system to control parking gate prototype. But none of all state clearly the characteristics of LED lamps used.

Typically by simulation any type of illumination generated by LED lamps will have a lambertian distribution[10]. When Line-of-Sight propagation model implemented, the angular distribution of the radiation intensity pattern using generalized Lambertian radiant intensity is formulated using equation (1) below.

$$
I(\varnothing)=I_{0} \cos (\varnothing)
$$

where I_ 0 corresponds to the incident ray which is parallel to the LED axis $(\varphi=0)$. I 0 is the maximum photometric intensity that will be transferred to the PD when both the LED and the PD are locked in a direct-line-of-sight (dLOS) position [5]. Since a Point-to-Point channel does not include any diffuse path, has a small angle beam, and, the transmitter and the receiver are locked in a permanent position, it can be modelled as a single mode Gaussian beam stochastic channel expressed as

$$
H_{0}=\frac{2 A_{l} e^{-\gamma L}}{\pi \theta_{1}^{2} L^{2}}
$$

where $A_{l}$ is the effective receiver area, $\theta$ the small angle beam divergence, $L$ the transmission range and $\gamma$ the intensity attenuation coefficient. It is to be noted that $\gamma$ depends on the phenomena such as haze, fog, snow and rain [11]. An experiment for outdoor VLC system using filter has been done in [12]. Several application for outdoor visible light communication has also been proposed in [13].

\section{Methods}

For ease of implementation, the system for outdoor lighting performance measurements are designed and arranged as on Fig.1. The system consists of VLC transmitter block which implemented using 8-bit microcontroller sending RS-232 serial data. It feeds the data to switching circuit using N-Channel MOSFET IRFZ44N which it can holds until $50 \mathrm{~V}$ and drive the LED arrays on outdoor lighting fixtures [14].

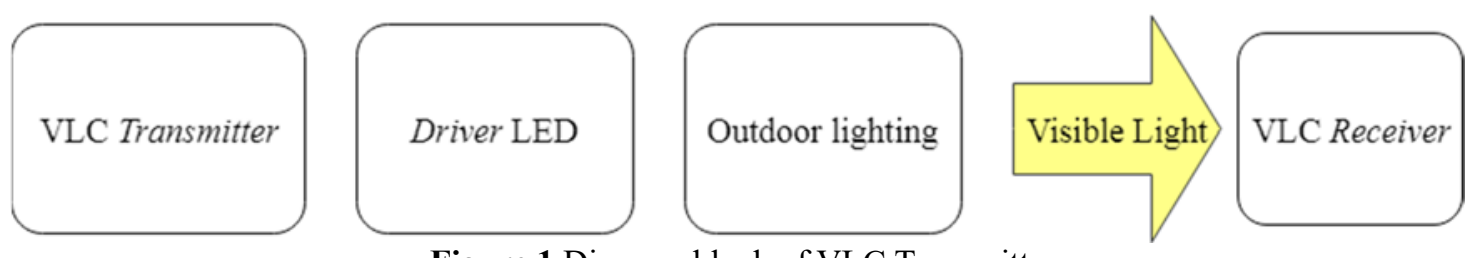

Figure 1 Diagram block of VLC Transmitter 
More specific, VLC transmitter block consists of an Arduino nano with ATMEGA328P microcontroller as data generator. Because every lamps work with different rating and working voltage as stated on Table 1, a simple switching circuit is needed to convert the volatage level. In this research a typical MOSFET circuits can work to fulfill the target. The LED drivers inherently turn on a series of LED lights, as well as controlling current and voltage automatically. Outdoor lighting lamps used as the VLC sending system are floodlight lamps, street light and motorcycle headlight as shown on Figure 2 and specified on Table-1. To test a successful data transmission system, a light to voltage sensor are used at the receiver side which receive its electrical signal to USB-to-TTL converter .

Tabel 1 Outdoor lighting specifications

\begin{tabular}{cccc}
\hline & LED Floodlight & LED Street Light & $\begin{array}{c}\text { LED motorcycle } \\
\text { headlamp }\end{array}$ \\
\hline Input voltage & $220 \mathrm{~V} \mathrm{AC}$ & $220 \mathrm{~V} \mathrm{AC}$ & $9-18 \mathrm{~V}$ AC/DC \\
\hline Driver Output voltage & $15 \mathrm{~V} \mathrm{DC}$ & $35 \mathrm{~V} \mathrm{DC}$ & $10,8 \mathrm{~V} \mathrm{DC}$ \\
\hline Power rating & $10 \mathrm{~W}$ & $12 \mathrm{~W}$ & HI 35W, LOW 20 W \\
\hline Light Intensity & $9001 \mathrm{~m}$ & $1050-11001 \mathrm{~m}$ & $35001 \mathrm{~m}$ \\
\hline
\end{tabular}

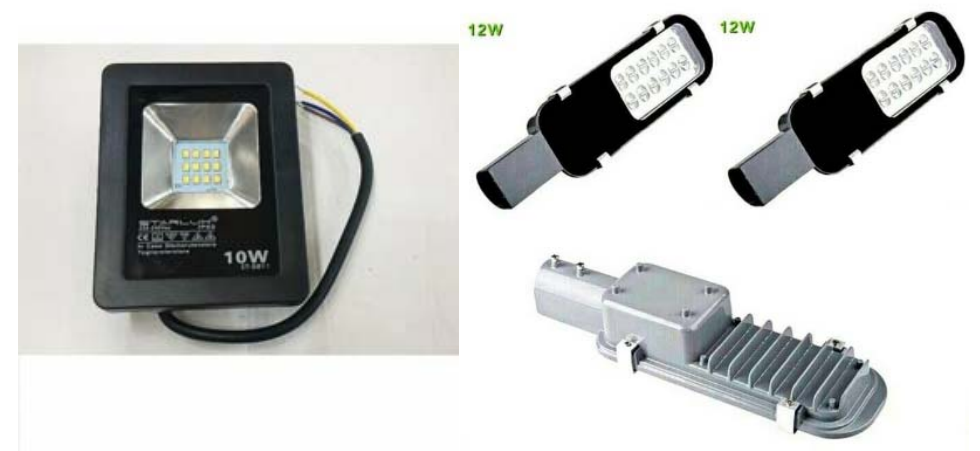

(a)

(b)

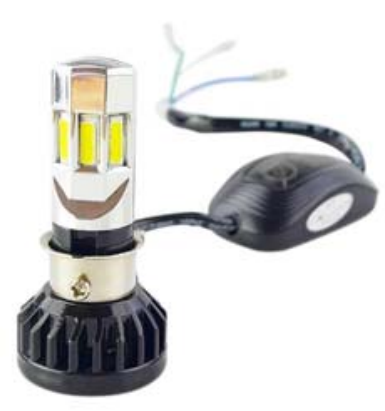

(c)

Figure 2 Type of outdoor lamps used (a) Floodlight lamp for Garden illumination (b) Streelight for street illumination (c) Motorcycle headlamp for motorcycle front illumination

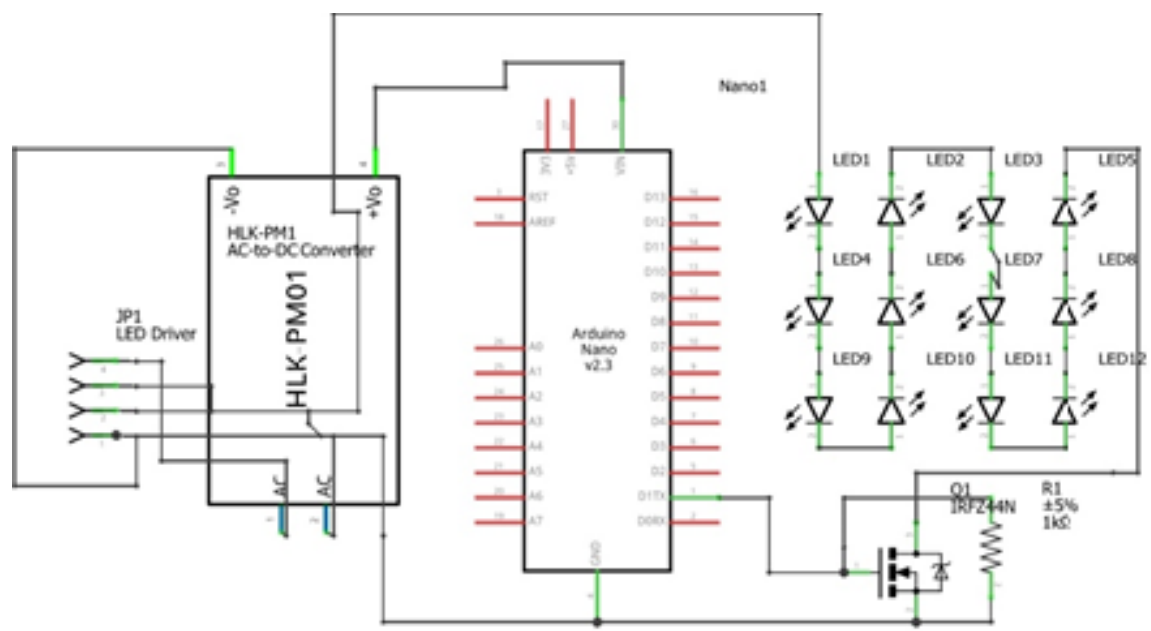

Figure 3 Schematic of VLC Transmitter 
Fig. 3 shows the complete VLC transmitter circuitry integrated to the system. The operating voltage as specified on Table-1 are 220VAC for floodlight and streetlight lamps, and 12V DC for motorcycle headlamp. To measure light intensity, a lux meter are used when data transmitted.

\section{Discussion}

When testing during in the daylight with a sunlight channel, the data can't be received using light to voltage sensor. Caused by the influence of sunlight which is brighter than the light.

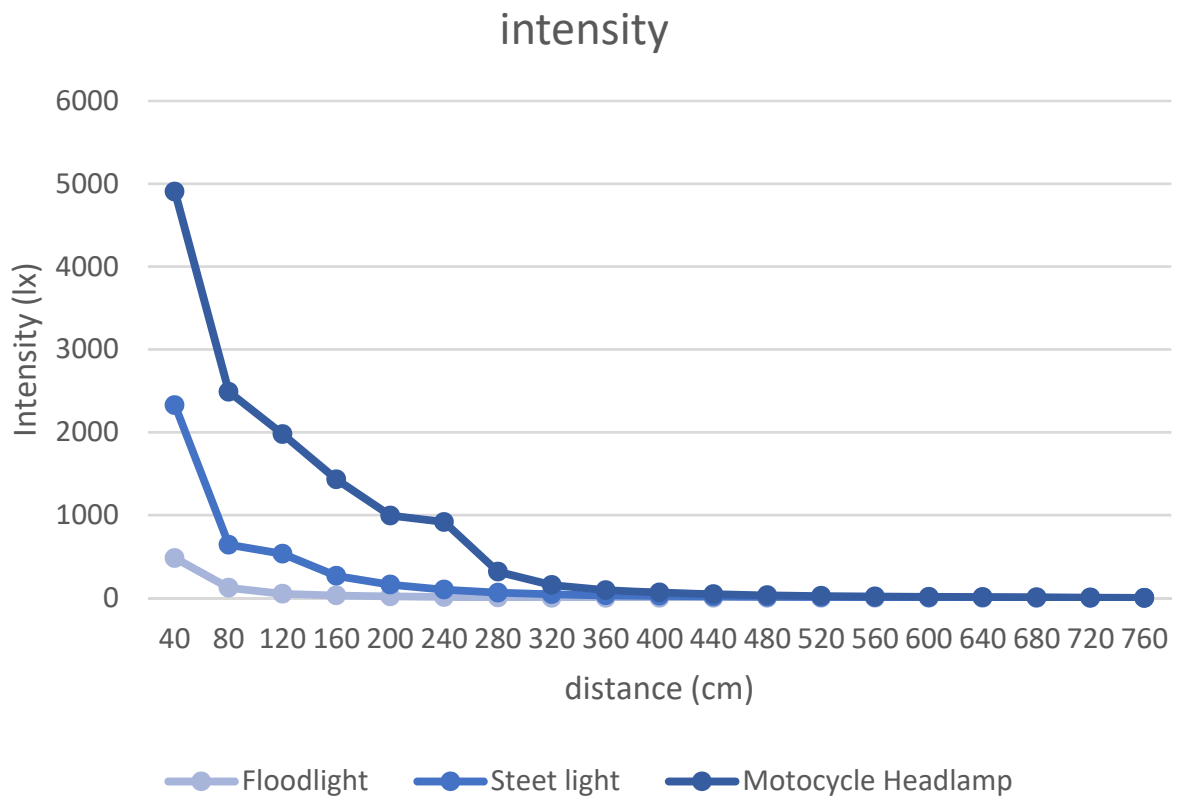

Figure 4 Intensity versus distance measurements results when data transmitted under ambient light environment

When testing at night with other lighting source without VLC, the data sent can still be received by outdoor lighting. But the data received from each outdoor lighting is not $100 \%$ perfect, due to the specifications of the lamp. Page lighting can only transmit data at a distance of $40 \mathrm{~cm}$, with a light intensity of 1-20 lx and with an angle of 0-60. Street lighting lights can transmit data up to $240 \mathrm{~cm}$, with a light intensity of 38-1204 lx and an angle of 0-60. Motorcycle lights can transmit data up to a distance of $80 \mathrm{~cm}$. But the data itself can only be received at an angle of 0 because the motor vehicle lights use a reflector, so the lamp has a light intensity of 10,489 $\mathrm{lx}$ at a distance of $40 \mathrm{~cm}$ and 4,504 $\mathrm{lx}$ at a distance of $80 \mathrm{~cm}$.

\section{Conclusion}

The data transmission system on VLC outdoor lighting lamps can use the IRFZ44N MOSFET as a conversion of dc to dc and load switching which is the transfer of data from Arduino to the LED driver. Sunlight greatly affects the sending and receiving of data on systems that have been implemented. While other sources of lighting that do not have VLC features do not significantly affect the delivery and reception systems. Garden lighting lamps can only transmit data at a distance of $40 \mathrm{~cm}$, with a light intensity of 1-20 lx and with an angle of 0-60. Street lighting lights can transmit data up to $240 \mathrm{~cm}$, with a light intensity of 38-1204 lx and an angle of 0-60. Motorcycle lights can transmit data up to a distance of $80 \mathrm{~cm}$. But the data itself can only be received at an angle of 0 because the motor vehicle lights use a 
reflector, so the lamp has a light intensity of 10,489 $\mathrm{lx}$ at a distance of $40 \mathrm{~cm}$ and 4,504 $\mathrm{lx}$ at a distance of $80 \mathrm{~cm}$. The power and driver of the LED from the lighting itself can affect the data sent.

\section{Conclusion}

We thank Diploma of Telecommunication Engineering, Applied Visible Light Communication Research Group and Laboratory of Telkom University Applied Science School for all support and contributions when conducting this research.

\section{References}

[1] K. Tae-Gyu, Advanced Optical Wireless Communication Systems, 1st ed. New York: Cambridge Universty Press, 2012.

[2] S. Rajagopal, R. D. Roberts, and S. K. Lim, "IEEE 802.15.7 visible light communication: Modulation schemes and dimming support," IEEE Commun. Mag., vol. 50, no. 3, 2012.

[3] T. Akiyama, "Time Synchronization Method Using Visible Light Communication for Smartphone Localization," no. c, pp. 6-9, 2016.

[4] V. M. Baeza, M. Sánchez-Fernández, A. G. Armada, and A. Royo, "Testbed for a LiFi system integrated in streetlights," 2015 Eur. Conf. Networks Commun. EuCNC 2015, pp. 517-521, 2015.

[5] A. Cailean et al., "Design and implementation of a visible light communications system for vehicle applications," 2015.

[6] T. Adiono and S. Fuada, "Investigation of Optical Interference Noise Characteristics in Visible Light Communication System," vol. 126, no. 126, 1990.

[7] D. H. Trihantoro, D. Darlis, and H. Putri, "Implementasi Visible Light Communication (VLC) Untuk Pengiriman Teks," in Seminar Nasional Teknologi Terapan, 2014.

[8] F. B. Aska, D. Darlis, and Hafidudin, "IMPLEMENTASI VISIBLE LIGHT COMMUNICATION (VLC) UNTUK PENGIRIMAN DATA DIGITAL," in eProceeding of Applied Science, 2015, vol. 1, no. 1, pp. 896-905.

[9] A. Ghevanarwianda, D. Darlis, and S. Aulia, "IMPLEMENTASI PERANGKAT VLC PADA LAMPU KENDARAAN UNTUK SISTEM KENDALI PALANG PINTU OTOMATIS," Universitas Telkom, 2017.

[10] S. Haruyama, "Visible light communication using sustainable LED lights," ITU Kaleidosc. Build. Sustain. Communities (K-2013), 2013 Proc., 2013.

[11] A. R. Ndjiongue and H. C. Ferreira, "An Overview of Outdoor Visible Light Communications," Trans. Emerg. Telecommun. Technol., vol. 29, no. 8, pp. 1-13, 2018.

[12] Y. Kim and Y. Chung, "Experimental Outdoor Visible Light Data Communication System Using Differential Decision Threshold with Optical and Color Filters," Opt. Eng., vol. 54, no. 4, p. 40501, 2015.

[13] M. Falcitelli and P. Pagano, Visible Light Communication for Cooperative ITS. Springer, 2016.

[14] H. Y, "ARDUINO-BASED HIGH POWERED SWITCHING LED DRIVERS." [Online]. Available: https://www.instructables.com/id/Arduino-based-High-Powered-Switching-LEDDrivers/. [Accessed: 15-Jun-2018]. 